\title{
Magnesium modulates doxorubicin activity through drug lysosomal sequestration and trafficking
}

\author{
Valentina Trapani, ${ }^{*}$ Francesca Luongo, Daniela Arduini and Federica I. Wolf \\ Istituto di Patologia Generale, Facoltà di Medicina e Chirurgia "A. Gemelli”, \\ Università Cattolica del Sacro Cuore, Rome
}

*Tel: 003906 30154914. E-mail: valentina.trapani@unicatt.it

\section{Supporting Information}

\section{Supplementary Figures}

- Figure S1. Sensitivity to DXR and nuclear drug accumulation in HC11 cell lines.

- Figure S2. DXR uptake in HC11 cell lines.

- Figure S3. The efflux pump inhibitor verapamil does not affect sensitivity to DXR and drug accumulation in $\mathrm{HC} 11$ cell lines.

- Figure S4. The lysosomal acidification inhibitor bafilomycin A increases nuclear DXR accumulation in HC11 cells. 


\section{Supplementary Figures}

Figure S1

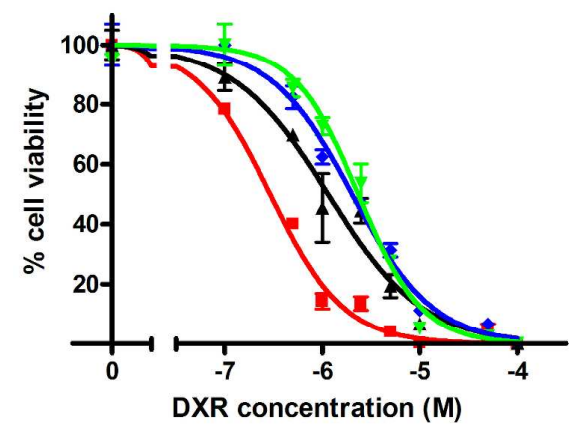

A
- Low-Mg

- $\mathrm{HC} 11$

- $\mathrm{HC} 11+\mathrm{Mg}$

v High-Mg

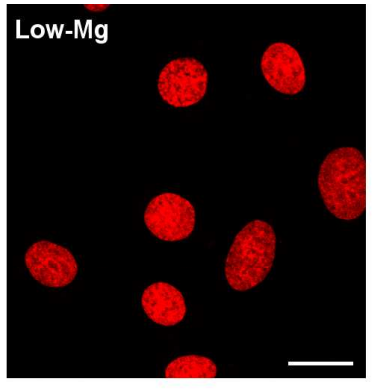

\section{$\mathrm{HC11+Mg}$}

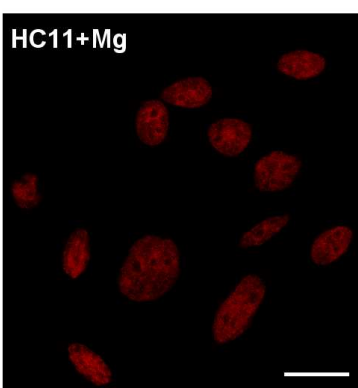

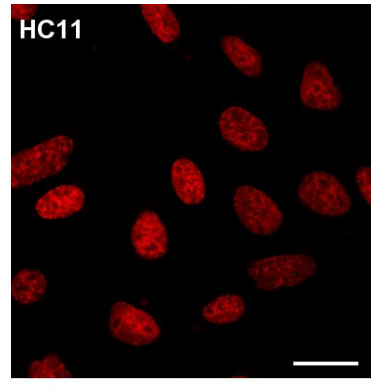

High-Mg

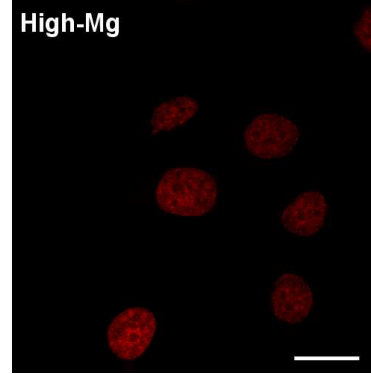

Figure S1. Sensitivity to DXR and nuclear drug accumulation in HC11 cell lines. (A) Dose-response curve of DXR, as determined by MTT assay at $24 \mathrm{~h}$. (B) Confocal images of DXR staining in cells fixed after a 2-h treatment with $10 \mu \mathrm{M}$ drug; scale bar: $20 \mu \mathrm{m}$. Where indicated, control HC11 cells were incubated in medium containing $10 \mathrm{mM} \mathrm{MgSO}_{4}$ for $24 \mathrm{~h}$ before drug addition.

\section{Figure S2}

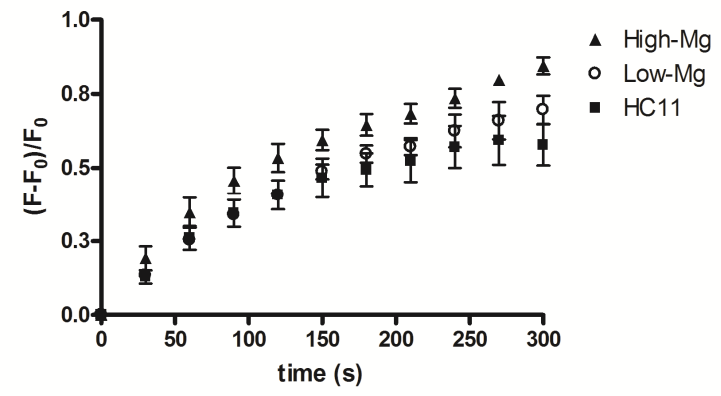

Figure S2. DXR uptake in HC11 cell lines. Cells were monitored by live confocal imaging following exposure to $50 \mu \mathrm{M}$ DXR ( $\mathrm{t}=0)$. Drug uptake was evaluated as the mean increase in intracellular fluorescence of 10 cells, and expressed as $\left(F-F_{0}\right) / F_{0}$, where $F_{0}$ indicates the fluorescence at the time of drug addition. Results are mean \pm SE $(n=3)$. 


\section{Figure S3}

A
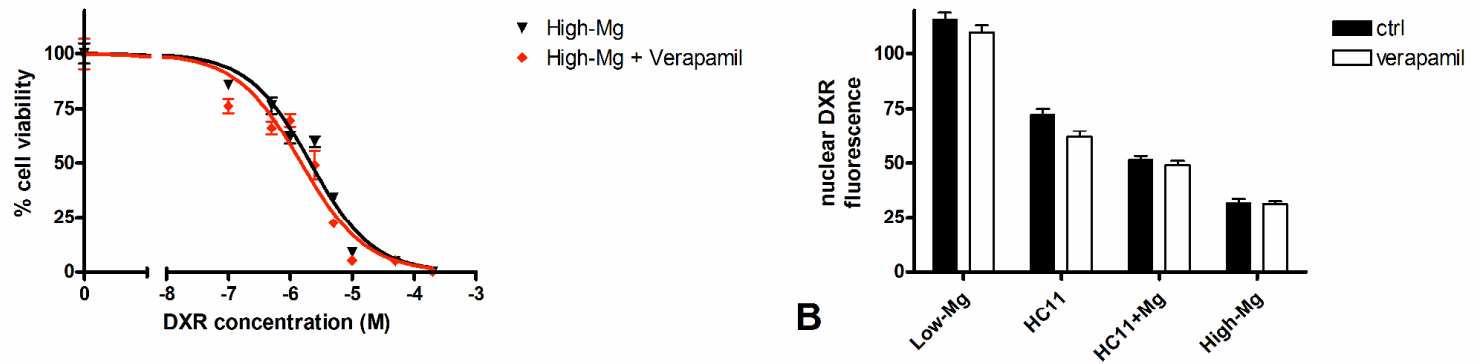

Figure S3. The efflux pump inhibitor verapamil does not affect sensitivity to DXR and drug accumulation in HC11 cell lines. (A) Dose-response curve of DXR in High-Mg cells. (B) Nuclear DXR accumulation in all strains, evaluated as the mean nuclear fluorescence intensity following DXR treatment $(10 \mu \mathrm{M}, 2 \mathrm{~h})$. Verapamil was used at a concentration of $5 \mu \mathrm{M}$.

Figure S4

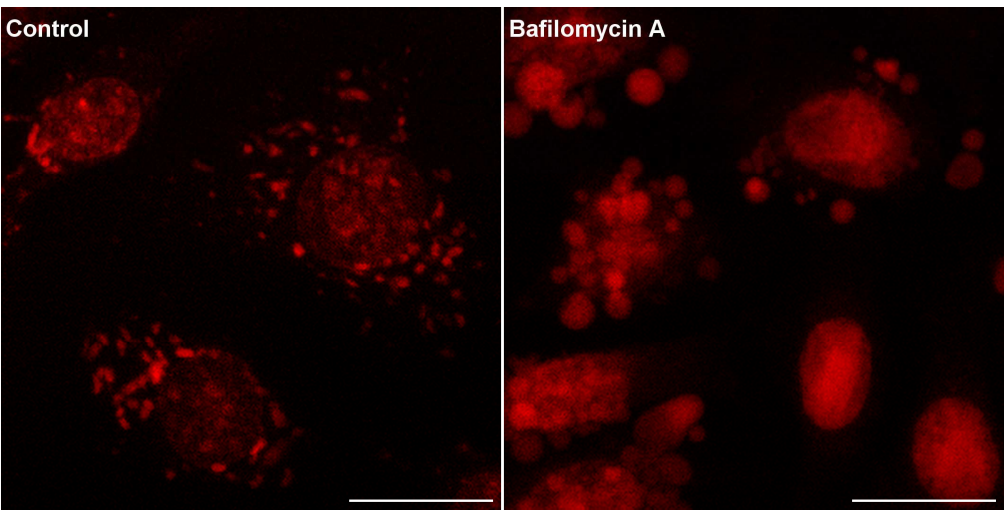

Figure S4. The lysosomal acidification inhibitor bafilomycin A increases nuclear DXR accumulation in HC11 cells. Cells were co-treated with DXR (1 $\mu \mathrm{M}, 24 \mathrm{~h})$ and bafilomycin (20 nM, 16h) and live imaged. Scale bar: $20 \mu \mathrm{m}$. Note the presence of fragmented apoptotic nuclei in bafilomycin-treated cells. Bafilomycin alone did not induce apoptosis (not shown). 